\title{
Dielectric properties of edible fungi powder related to radio-frequency and microwave drying
}

Siying Qi $i^{1,2}$, Jiping Han ${ }^{1,3}$, Camel Lagnika ${ }^{1}$, Ning Jiang ${ }^{1,2,3^{*}}$, Chunlu Qian ${ }^{2}$, Chunquan Liu ${ }^{1}$, Dajing Li ${ }^{1}$, Yang TaO ${ }^{4}$, Zhifang Yu', Libin Wang ${ }^{4}$, Zhongyuan Zhang ${ }^{1}$, Chunju Liu', Yadong Xiao' and Min Zhang ${ }^{5}$

\begin{abstract}
Edible fungi are rich in nutrition, but they are susceptible to spoilage, and often prolonged by drying. RF and microwave energy drying have the advantages of short drying time, high energy efficiency and good process control. However, to develop an effective dielectric drying method, it is important to understand dielectric properties, the major factor characterizing the interaction between the electromagnetic energy and the food. At present, there is a lack of research on dielectric properties of edible fungi. In this study, a vector network analyzer and an open-ended coaxial-line probe were employed to measure the dielectric parameters. The dielectric parameters were observed at different temperatures $\left(25-85^{\circ} \mathrm{C}\right)$ for edible fungi powder with moisture content ranging from 5 to $30 \%$ wet basis over a frequency range of 1-3000 $\mathrm{MHz}$. The relationship between the dielectric properties and frequency, temperature, and moisture content were obtained via regression analysis. Further, the dielectric penetration depth was calculated, and the effects of frequency, moisture content, and temperature on the penetration depth were also analyzed. The results showed that the dielectric properties of edible fungi powder increased with an increase in moisture content and temperature, while they decreased with increasing frequency. At high moisture content and temperature, the increase in dielectric properties was slightly larger than that at low moisture content and temperature. The dielectric properties changed more evidently at lower radio frequencies than at higher radio frequencies. The penetration depth decreased with an increase in temperature, moisture content, and frequency. It can be concluded that a large penetration depth at radio frequencies below $100 \mathrm{MHz}$ could be used to dry edible fungi on a large scale, whereas microwave energy could be employed for drying edible fungi on a small scale.
\end{abstract}

Keywords: Edible fungi, Dielectric properties, Dielectric drying, Dielectric constant, Dielectric loss factor, Mathematical modeling

\section{Introduction}

Edible fungi (mushrooms) have a large fruiting body, taste delicious, and have high edible, medicinal, and economic values (Sun et al. 2019; Xue et al. 2019). Edible fungi are a healthy food with significant therapeutic

\footnotetext{
*Correspondence: jaas_jiangning@163.com

'Institute of Farm Product Processing, Jiangsu Academy of Agricultural

Sciences, Nanjing 210014, People's Republic of China

${ }^{2}$ College of Food Science and Engineering, Yangzhou University, Yangzhou

225127, People's Republic of China

Full list of author information is available at the end of the article
}

effects and are rich in bioactive compounds, including polysaccharides (e.g., $\alpha$ - and $\beta$-glucan), proteins, peptides, polyphenols, terpenoids, vitamins, and dietary fiber (Khan \& Tania, 2012; Reis et al. 2012; Yan et al. 2018). The most reasonable and balanced dietary structure in the twenty-first century is "one meat, one vegetable, and one mushroom," indicating that edible fungi occupy an extremely important position in human diet (Manzi et al. 2001). At present, China is the world's largest producer of edible fungi, accounting for more than $70 \%$ of

(c) The Author(s). 2021 Open Access This article is licensed under a Creative Commons Attribution 4.0 International License, which permits use, sharing, adaptation, distribution and reproduction in any medium or format, as long as you give

appropriate credit to the original author(s) and the source, provide a link to the Creative Commons licence, and indicate if changes were made. The images or other third party material in this article are included in the article's Creative Commons licence, unless indicated otherwise in a credit line to the material. If material is not included in the article's Creative Commons licence and your intended use is not permitted by statutory regulation or exceeds the permitted use, you will need to obtain permission directly from the copyright holder. To view a copy of this licence, visit http://creativecommons.org/licenses/by/4.0/ 
the world's total production. However, due to the late development of storage and processing technology of edible fungi in China, the technology is relatively backward, restricting the advancement of the edible fungi industry (Sun et al. 2019). Particularly when edible fungi are in season, they are abundant, and the overstocking of products causes extremely heavy economic losses (Walde et al. 2005). Drying processes can be used to reduce the moisture content of edible fungi, preventing the growth and propagation of microorganisms and biological enzyme activity (Su et al. 2020; Tian et al. 2016). The dried product is convenient for long-term storage and transportation. Therefore, research on the drying and storage of edible fungi, methods of drying, and drying conditions is the top priority in the development of the current edible fungi industry.

Drying of edible fungi is a cost-effective and popular processing method (Wang et al. 2017). It has been experimentally shown that the use of radio-frequency (RF) drying is better than conventional heating and drying (Zhao et al. 2018). RF and microwave energy drying have the advantages of short drying time, high energy efficiency, good process control, small footprint, and quick startup and downtime. Microwave-assisted air drying shortened the drying time of mushrooms by four times compared with that of hot air (Ewa et al. 2019). The studies have shown that dielectric drying can significantly improve the drying process of foods in lowmoisture foods (Wang et al. 2020; Zhou et al. 2018a, b).

The thermal process of food is a significantly complicated processing, involving various changes and transmissions of calories (Cong et al. 2012). Therefore, attention should be paid to the selection of relevant conditions when using dielectric heating. The most important material characteristic to control dielectric heating is the dielectric permittivity $\varepsilon=\varepsilon^{\prime}-\mathrm{j} \varepsilon^{\prime \prime}$ of the material, namely, the dielectric constant, $\varepsilon^{\prime}$, and loss factor, $\varepsilon "$ (Lau \& Subbiah, 2018). These are influenced by the applied frequency the material temperature and moisture (Guo et al. 2009; Zhu et al. 2012; Guo \& Zhu, 2014). The application of dielectric heating for disinfestation, drying, pasteurization, and thawing has been studied by many scholars (Bedane et al. 2017; Li et al. 2018; Ling et al. 2016; Li et al. 2017; Nagaraj et al. 2016; Zheng et al. 2017; Zhou et al. 2017; Zhou et al. 2018a, b). However, there is no specific research on the dielectric properties of edible fungi powder in the frequency range of 1$3000 \mathrm{MHz}$, and the relationship between the dielectric properties of edible fungi powder and their influencing factors.

To provide useful information for equipment and process design during the deceleration stage of drying edible fungi with dielectric drying, the dielectric properties of five types of edible fungi powder with a moisture content of 5-30\% were measured. For this purpose, an open coaxial probe and vector network analyzer were used, and the temperature and frequency ranges were $25-85^{\circ} \mathrm{C}$ and $1-3000 \mathrm{MHz}$, respectively. Furthermore, mathematical models were used to describe the dependence of the dielectric properties of edible fungi powder on frequency, moisture content, and temperature. The penetration depth of these five types of edible fungi powder was also calculated.

\section{Materials and methods \\ Raw materials}

The test materials were selected from five types of edible fungi, including Pleurotus eryngii, Flammulina velutipes, Velvet mushroom, Agaricus bisporus, and Straw mushroom, which were ordered from the local market. Before the experiment, the edible fungi were washed, diced, and dried in an oven at $55^{\circ} \mathrm{C}$ for more than $10 \mathrm{~h}$, and then converted into a powder using a pulverizer. After passing through an 80-mesh sieve, the initial moisture content of the edible fungi powder sample was determined.

\section{Pretreatment of samples}

Samples that were ground into powder and sieved through 80-mesh sieves were weighed and sampled into six parts of approximately $100 \mathrm{~g}$ using an electronic balance and placed in evaporating dishes. The powder samples with moisture contents of $5,10,15,20,25$, and $30 \%$ were prepared by spraying water on 100 -g powder samples with a fine-hole spray pot, and then they were placed in completely sealed bags. The samples were stored in a refrigerator at $4{ }^{\circ} \mathrm{C}$ for $24 \mathrm{~h}$, and the bags were shaken four to six times a day to obtain a uniform moisture distribution throughout the sample.

\section{Determination of moisture content}

The initial moisture content of the sample and the actual moisture content of the finished sample were determined via the $105^{\circ} \mathrm{C}$ constant weight method. First, a clean aluminum flat weighing dish was placed in a $105^{\circ} \mathrm{C}$ drying box to heat for $0.5-1.0 \mathrm{~h}$, and the dish lid was obliquely supported on the side of the dish. Subsequently, the cover was taken out and placed in a desiccator for $0.5 \mathrm{~h}$, and then weighed and recorded (repeated drying was required to obtain constant weight). Next, an accurately weighed 2-g sample (accurate to $0.0001 \mathrm{~g}$ ) with a thickness of approximately $5 \mathrm{~mm}$ was placed into the weighing dish and covered and weighed. The weight was recorded. Subsequently, the weighing dish with sample was place in a drying oven at $105^{\circ} \mathrm{C}$, weighing dish lid was obliquely supported on the side of the dish. After $4 \mathrm{~h}$ of drying, the weighing dish with sample was removed and placed in the desiccator for $0.5 \mathrm{~h}$ and 
weighed. Then, it was placed in a drying oven at $105^{\circ} \mathrm{C}$ for $1 \mathrm{~h}$, taken out, cooled in the desiccator for $0.5 \mathrm{~h}$, and then weighed. The difference in mass between the measurements before and after drying was not more than $0.002 \mathrm{~g}$, which implied a constant weight. Subsequently, the moisture content of the sample was calculated.

\section{Determination of temperature}

The temperature required for the experiment was set using a constant-temperature water bath to uniformly heat the sample, and the temperature of the sample was calculated using a thermocouple thermometer. In order to accurately determine the temperature change of the sample during the measurement process, the probe of the thermocouple thermometer was inserted inside the sample and fixed.

\section{Determination of dielectric properties}

The experimental system consisted of a computer, an E5061B vector network analyzer (Agilent Corporation, USA), an open coaxial probe (Agilent Corporation, USA), a constant-temperature water bath, a temperature control unit, and a lifting platform (Jintan Science and Technology Instrument Co., Ltd.). The computer was employed to control the system and record the date and data. The sample temperature was monitored by a Ttype thermocouple thermometer with a measurement accuracy of $0.1^{\circ} \mathrm{C}$. The laboratory lifting platform was used to change the water bath height. A schematic diagram of the dielectric properties measurement system is shown in Fig. 1.

Before the measurement experiment, the vector network analyzer was turned on to warm up approximately $30 \mathrm{~min}$. Then, the vector network analyzer and the coaxial probe with an open-end were calibrated. The network analyzer was calibrated using deionized water, air, and short circuit, and the sensitivity of the open coaxial probe was tested as suggested by Lau et al. (2020).

After the calibration, for each moisture level, approximately $15 \mathrm{~g}$ of edible fungi powder was put in a stainless-steel cylindrical sample holder (inner diameter $30 \mathrm{~mm}$, height $10 \mathrm{~mm}$ ) with bulk density about $3.18 \mathrm{~g} /$

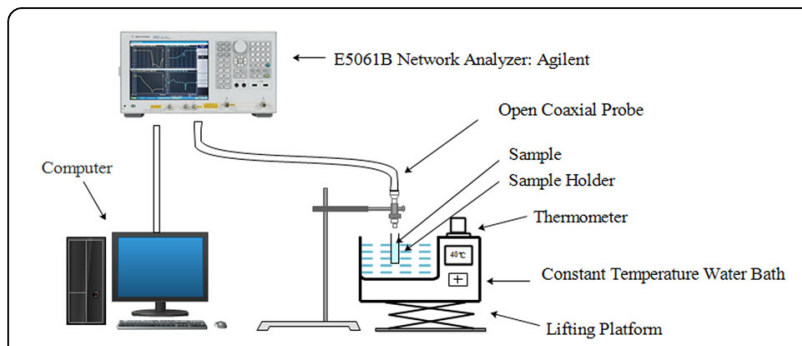

Fig. 1 a Schematic diagram of dielectric properties measurement system $\mathrm{cm}^{3}$ fixed in a constant-temperature water bath to avoid heat loss as much as possible. It was ensured that the open coaxial probe fitted snugly against the surface of the sample and maintained adequate pressure to avoid air gaps in the measurement process. Further, a thermocouple was inserted in the center of the sample to monitor the temperature of the sample.

The dielectric properties of edible fungi powder at different moisture contents and temperatures were measured. The dielectric constant and dielectric loss factor were read by a computer, and the data were saved. During the experiment, the ambient temperature was controlled as approximately $23{ }^{\circ} \mathrm{C}$, and the height of the water bath was controlled by the laboratory lifting platform. The temperature of the circulating water in the water bath was set to $25,35,45,55,65,75$, and $85^{\circ} \mathrm{C}$ consecutively in intervals of $10^{\circ} \mathrm{C}$. After the sample temperature reached the specified value, the dielectric properties were determined three times in $2 \mathrm{~min}$, and the mean value was calculated.

The mathematical formula proposed by Auksornsri to describe the dielectric constant and dielectric loss factor of pure polar materials could be expressed as follows (Auksornsri et al., 2018):

$$
\begin{aligned}
& \varepsilon^{\prime}=\varepsilon_{\infty}+\frac{\varepsilon_{\mathrm{s}}-\varepsilon_{\infty}}{1+(2 \pi f)^{2} \mathrm{~T}^{2}} \\
& \varepsilon^{\prime \prime}=\frac{\left(\varepsilon_{\mathrm{s}}-\varepsilon_{\infty}\right) \cdot 2 \pi \mathrm{f} \mathrm{\tau}}{1+(2 \pi f)^{2} \mathrm{\tau}^{2}}
\end{aligned}
$$

where the dielectric constant $\varepsilon_{\infty}$ indicates that the molecular orientation does not have sufficient time to promote polarization when the frequency is close to infinity, $\varepsilon_{\mathrm{s}}$ stands for the static dielectric constant, i.e., the value at zero frequency, $f$ represents the frequency $(\mathrm{MHz})$, and $\tau$ denotes the relaxation time (s), the time when the period related to the dipole time recovers in a random direction after removing the electric field.

\section{Effect of frequency on dielectric properties}

The sample moisture content was $5-30 \%$ with an interval of 5\% (a total of six moisture contents) and the temperature range was $25-85^{\circ} \mathrm{C}$ with an interval of $10^{\circ} \mathrm{C}$ (a total of six temperatures). The moisture content and temperature of the experimental sample were controlled, and the frequency was set to $1-3000 \mathrm{MHz}$. The effect of the frequency on the dielectric properties was studied.

\section{Effect of temperature on dielectric properties}

The sample temperature was controlled using a digital constant-temperature water bath. The moisture content was $5-30 \%$, with an interval of $5 \%$, and a total of six moisture content intervals. The frequency was set 
to $1-3000 \mathrm{MHz}$. The moisture content and frequency of the sample were controlled, and the effect of temperature on the dielectric properties was studied from $25^{\circ} \mathrm{C}$ to $85^{\circ} \mathrm{C}$ in increments of $10^{\circ} \mathrm{C}$.

\section{Effect of moisture content on the dielectric properties}

The sample moisture content was controlled using a spray pot. The temperature range was $25-85^{\circ} \mathrm{C}$, with a total of seven temperature intervals in increments of $10^{\circ} \mathrm{C}$. The frequency was set to $1-3000 \mathrm{MHz}$. The temperature and frequency of the sample were controlled, and the effect of moisture content on dielectric properties was studied.

\section{Microwave penetration depth}

The penetration depth is defined as the distance at which the microwave power is decreased to $1 / \mathrm{e}(\mathrm{e}=$ 2.718) of that at the surface. The penetration depth is an important parameter for evaluating the heating uniformity during microwave heating (Erdogdu et al. 2015). The following equation was used to calculate the penetration depth:

$$
\mathrm{d}_{\mathrm{p}}=\frac{\mathrm{c}}{2 \pi \mathrm{f} \sqrt{2 \varepsilon^{\prime}\left[\sqrt{1+\left(\frac{\varepsilon^{\prime \prime}}{\varepsilon^{\prime}}\right)^{2}}-1\right]}}
$$

where $d_{p}, c, f, \varepsilon^{\prime}$, and $\varepsilon^{\prime \prime}$ represent the penetration depth $(\mathrm{m})$, speed of light in free space $\left(3 \times 10^{8} \mathrm{~m} \mathrm{~s}^{-1}\right)$, frequency of microwave $(\mathrm{MHz})$, measured dielectric constant, and measured dielectric loss factor value, respectively.

\section{Statistical analysis}

All experiments were repeated at least three times, and the data were expressed as mean \pm standard deviation. Microcal Origin 9.0 (Microcal Software, Inc., Northampton, USA) software and SPSS 19.0 computer program (SPSS Inc., Chicago, IL, USA) were employed for statistical analysis. Regression analysis was performed to determine the significant probability for moisture content, frequency, and temperature to affect the dielectric constant and dielectric loss constant.

\section{Results and discussion}

\section{Effect of frequency on dielectric properties}

Figure 2 shows the frequency-dependent dielectric properties $\left(\varepsilon^{\prime}\right.$ and $\left.\varepsilon^{\prime \prime}\right)$ of Pleurotus eryngii powder with a moisture content of 12.0 and $30.9 \%$ at a temperature of $25-85^{\circ} \mathrm{C}$ in the frequency range of 1-3000 MHz. From Fig. 2, both $\varepsilon^{\prime}$ and $\varepsilon^{\prime \prime}$ are affected by the frequency. In the studied frequency range, the dielectric constant $\varepsilon^{\prime}$ decreases with frequency, and the trend is more evident at low frequencies. The dielectric loss factor $\varepsilon$ " decreases significantly with the increase in frequency. For instance, when the temperature is $75^{\circ} \mathrm{C}$, the frequency increases from $27 \mathrm{MHz}$ to $915 \mathrm{MHz}$ and the dielectric constant of Pleurotus eryngii powder with a moisture content of $12.0 \%$ decreases from 19.22 to 9.31 , which represents a decrease of approximately $51.6 \%$. Similarly, the dielectric loss factor decreases from 18.22 to 2.88, which denotes a reduction of approximately $84.2 \%$. Furthermore, when the frequency continues to increase to $2450 \mathrm{MHz}$, the dielectric constant reduces from 9.31 to 7.43 , which is a decrease of approximately $20.2 \%$, and the dielectric loss factor increases slightly to 3.44. This result is consistent with those reported by Zhang et al. (2016) and Zhou et al. (2018a, b).

At higher temperatures $\left(>45^{\circ} \mathrm{C}\right)$, the effect of frequency on dielectric constant $\varepsilon^{\prime}$ and dielectric loss factor $\varepsilon$ " is more prominent than that at lower temperatures. For example, when the frequency is increased from 27 $\mathrm{MHz}$ to $2450 \mathrm{MHz}$, the dielectric constant of Pleurotus eryngii powder with a moisture content of $12.0 \%$ is reduced from 3.64 to 2.44 at $25^{\circ} \mathrm{C}$, but significantly decreases from 15.99 to 9.27 at $85^{\circ} \mathrm{C}$, respectively. The dielectric loss factor decreases from 0.79 to 0.29 at $25^{\circ} \mathrm{C}$ and from 35.94 to 3.90 at $85^{\circ} \mathrm{C}$ respectively.

In addition, the effect of frequency on the dielectric constant and dielectric loss factor is more evident at high moisture content than that at low moisture content. For instance, at $25^{\circ} \mathrm{C}$, when the frequency is increased from $27 \mathrm{MHz}$ to $2450 \mathrm{MHz}$, the dielectric constant of the sample with a moisture content of $12.0 \%$ decreases from 3.64 to 2.44, and the dielectric constant of the sample with a moisture content of $30.9 \%$ decreases from 23.04 to 8.74 , depicting reductions of 33.0 and $62.1 \%$, respectively, and this result is similar to that reported by Auksornsri et al. (2018). Further, the dielectric loss factor value of the sample with a moisture content of $12.0 \%$ decreases from 0.79 to 0.29 , while the sample with $30.9 \%$ moisture content decreases from 21.44 to 3.68 , indicating reductions of 63.3 and $82.8 \%$, respectively.

A similar frequency-dependent dielectric constant $\varepsilon$ ' and dielectric loss factor $\varepsilon$ " were also found in samples of Pleurotus eryngii powder with other moisture contents. As shown in Figs. 3 and 4, the other four edible fungi also have the same frequency-dependent dielectric properties as those of Pleurotus eryngii.

Equations (1) and (2) show that $\varepsilon^{\prime}$ and $\varepsilon^{\prime \prime}$ are determined by $\varepsilon_{s}, \varepsilon_{\infty}, \tau$, and $\mathrm{f}$. At a specified temperature, $\varepsilon_{s}$, $\varepsilon_{\infty}$, and $\tau$ are almost constant. Evidently, $\varepsilon^{\prime}$ and $\varepsilon^{\prime \prime}$ are negatively correlated with the square of the frequency. This is the reason why $\varepsilon^{\prime}$ and $\varepsilon^{\prime \prime}$ of Pleurotus eryngii powder decrease with an increase in frequency. The reason that $\varepsilon$ 'rises substantially and tends to be gradual at 

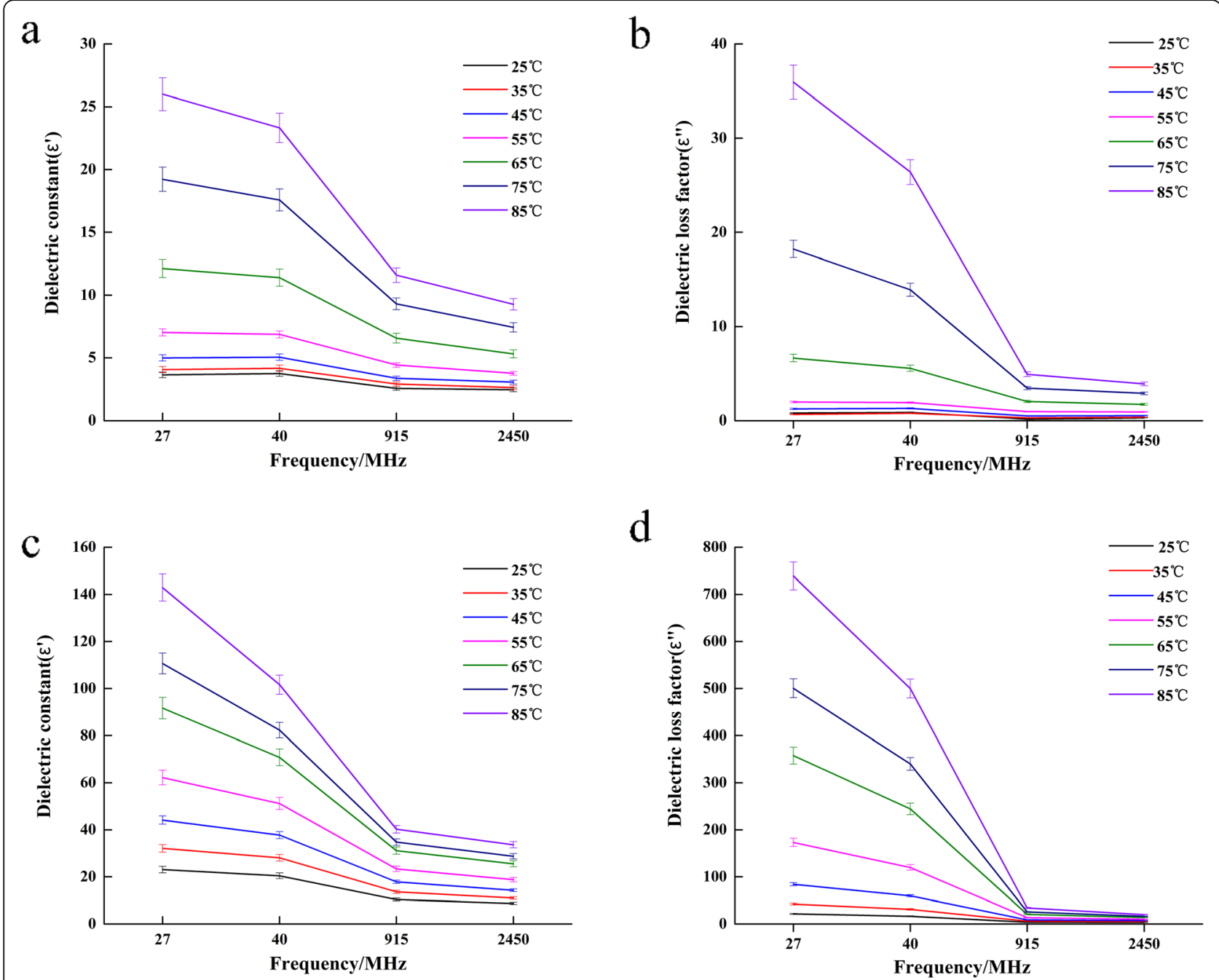

Fig. 2 Effect of frequency on dielectric constant $\varepsilon^{\prime}$ and dielectric loss factor $\varepsilon^{\prime \prime}$ at different temperatures of Pleurotus eryngii powder samples with moisture content of 12.0 and $30.9 \%$ a Dielectric constant $\left(\varepsilon^{\prime}\right)$ with moisture content of $12.0 \%$, b dielectric loss factor $\left(\varepsilon^{\prime \prime}\right)$ with moisture content of $12.0 \%$, c dielectric constant $\left(\varepsilon^{\prime}\right)$ with moisture content of $30.9 \%$, dielectric loss factor $\left(\varepsilon^{\prime \prime}\right)$ with moisture content of $30.9 \%$

high frequencies is that the negative linear relationship between $\varepsilon^{\prime}$ and frequency is caused by ion conduction. In the lower RF range and at higher microwave frequencies, ion conduction and dipole polarization are the main loss mechanisms, respectively.

\section{Effect of temperature on dielectric properties}

The dielectric constant $\varepsilon^{\prime}$ and the dielectric loss factor $\varepsilon$ " of the Pleurotus eryngii powder at temperatures of 25$85^{\circ} \mathrm{C}$, frequencies of $27,40,915$, and $2450 \mathrm{MHz}$, and a moisture content of $21.2 \%$ are shown in Fig. 5 . At the four frequencies, the dielectric constant $\varepsilon^{\prime}$ and dielectric loss factor $\varepsilon$ " increase with increasing temperature. At high frequencies (915 and $2450 \mathrm{MHz}$ ), the dielectric constant and dielectric loss factor vary slightly with temperature, especially the dielectric loss factor. At low frequencies (27 and $40 \mathrm{MHz}$ ), the dielectric constant and the dielectric loss factor change rapidly, especially at temperatures above $45^{\circ} \mathrm{C}$. For example, when the temperature increases from $25^{\circ} \mathrm{C}$ to $85^{\circ} \mathrm{C}$, for the sample with a moisture content of $21.2 \%$ at $27 \mathrm{MHz}$, the dielectric constant increases from 8.25 to 70.94 , and the dielectric loss factor increases from 2.34 to 368.36, increasing by 88.4 and $99.4 \%$, respectively. At $915 \mathrm{MHz}$, the dielectric constant and the dielectric loss factor increase from 5.45 and 0.97 to 30.50 and 19.74, increasing by 82.1 and $95.1 \%$, respectively. Similar temperaturedependent dielectric properties were also observed at other moisture levels for Pleurotus eryngii powder. From Fig. 6, the other four edible fungi also have the same temperature-dependent dielectric properties as those of Pleurotus eryngii. 

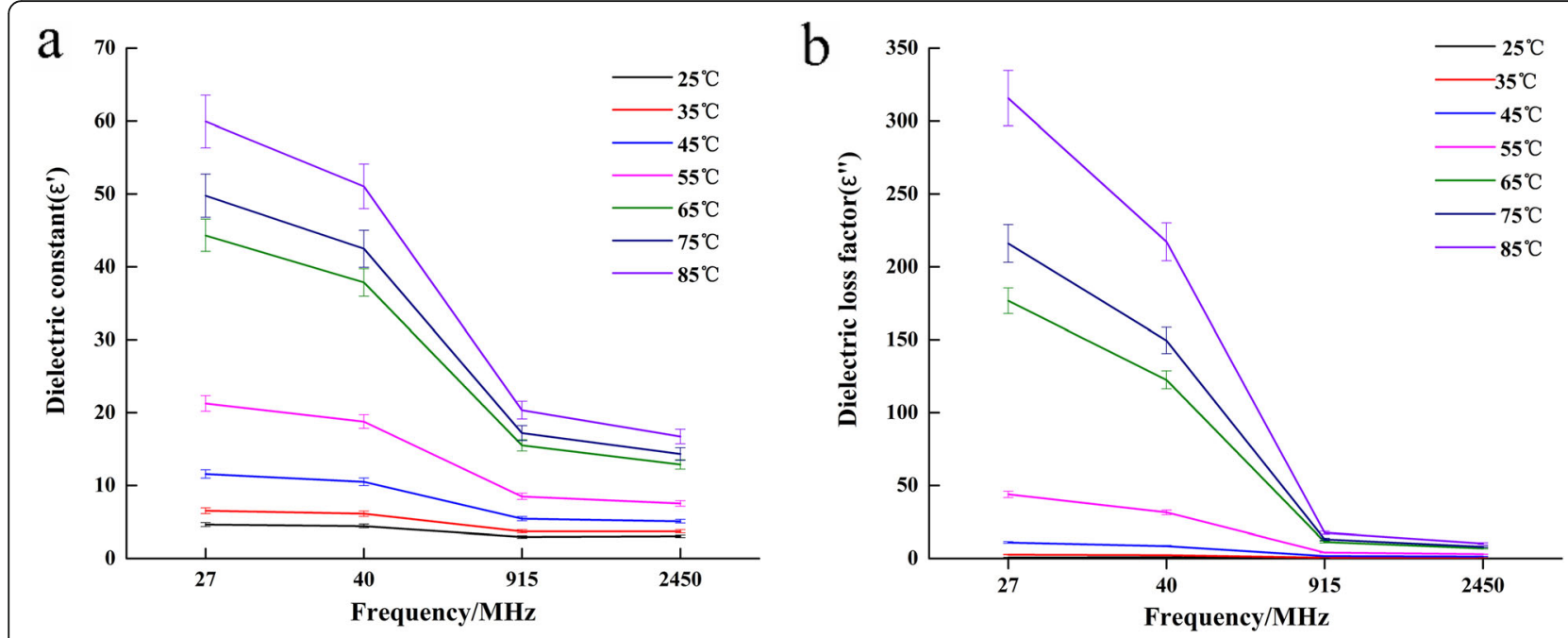

Fig. 3 Effect of frequency on dielectric constant $\varepsilon^{\prime}$ and dielectric loss factor $\varepsilon^{\prime \prime}$ at different temperatures of Agaricus bisporus powder samples with moisture content of $16.7 \%$ a Dielectric constant $\left(\varepsilon^{\prime}\right)$ with moisture content of $16.7 \%$, b dielectric loss factor $\left(\varepsilon^{\prime \prime}\right)$ with moisture content of $16.7 \%$

The increase in temperature leads to an increase in Brownian motion and the static dielectric constant, therefore the dielectric constant increases with increasing temperature. The dielectric loss factor is related to the dissolved ions in the sample, and the increase in temperature improves ion mobility and ion conduction, resulting in an increase in the dielectric loss factor in the studied frequency range.

\section{Effect of moisture content on dielectric properties}

Figure 7 shows the effect of the moisture content of Pleurotus eryngii powder on the dielectric constant ' $\varepsilon$ ' and the dielectric loss factor $\varepsilon$ " at seven study temperatures at $915 \mathrm{MHz}$. Both $\varepsilon^{\prime}$ and $\varepsilon^{\prime \prime}$ increase with increasing moisture content and change rapidly when the moisture content is above $15.0 \%$. In addition, the rate of increase at higher temperatures is slightly larger than that at low temperatures. For instance, at $25^{\circ} \mathrm{C}$, as the moisture content of the sample rises from 9.9 to $30.9 \%$, the dielectric constant $\varepsilon^{\prime}$ increases from 2.60 to 10.36 and the dielectric loss factor increases from 0.15 to 1.16 , which represent increases of 75.0 and $87.0 \%$, respectively. Similarly, at $85^{\circ} \mathrm{C}$, as the moisture content of the sample increases from 9.9 to $30.9 \%$, the dielectric constant $\varepsilon^{\prime}$ increases from 5.73 to 40.25 and the dielectric loss factor increases from 3.93 to 33.94, which denote increases of 85.8 and $88.4 \%$, respectively. Similar moisture contentdependent dielectric properties were also observed at
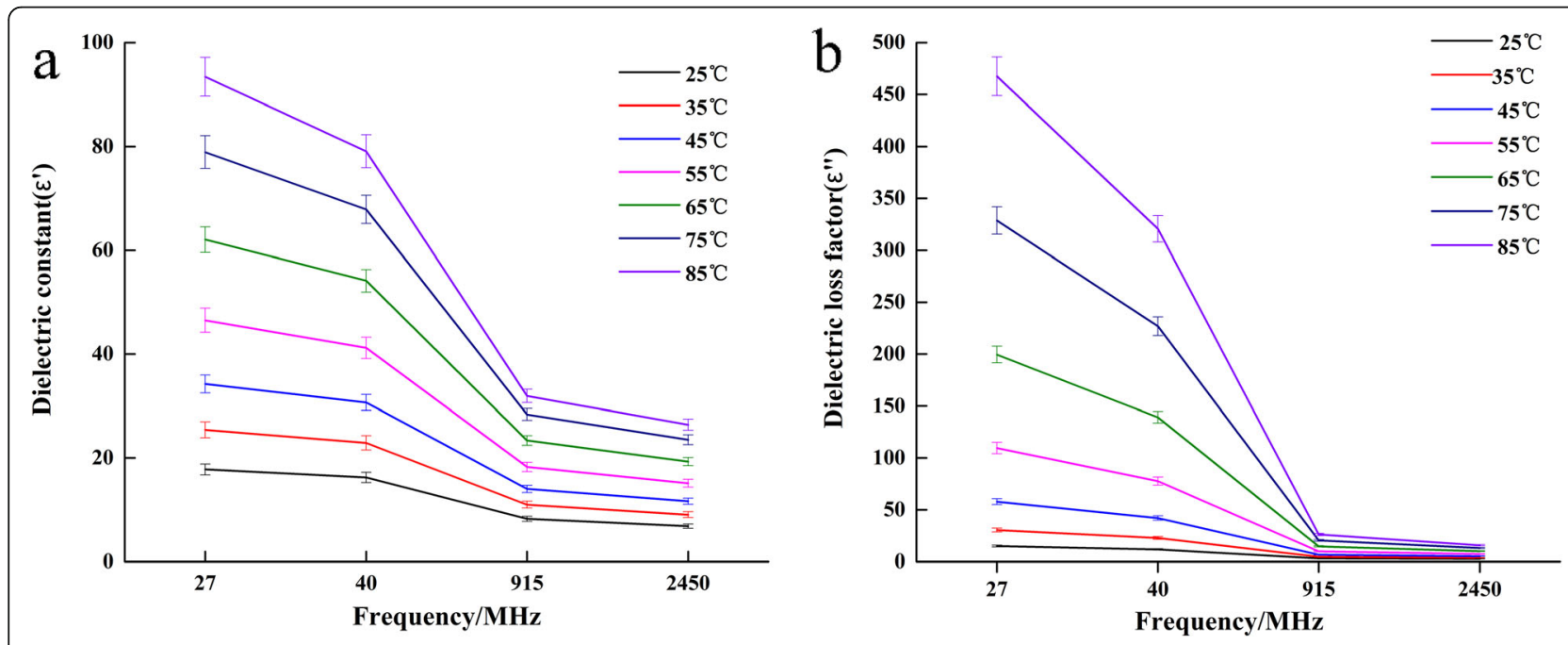

Fig. 4 Effect of frequency on dielectric constant $\varepsilon^{\prime}$ and dielectric loss factor $\varepsilon^{\prime \prime}$ at different temperatures of Straw mushroom powder samples with moisture content of $25.0 \%$ a dielectric constant $\left(\varepsilon^{\prime}\right)$ with moisture content of $25.0 \%$, b dielectric loss factor $\left(\varepsilon^{\prime \prime}\right)$ with moisture content of $25.0 \%$ 

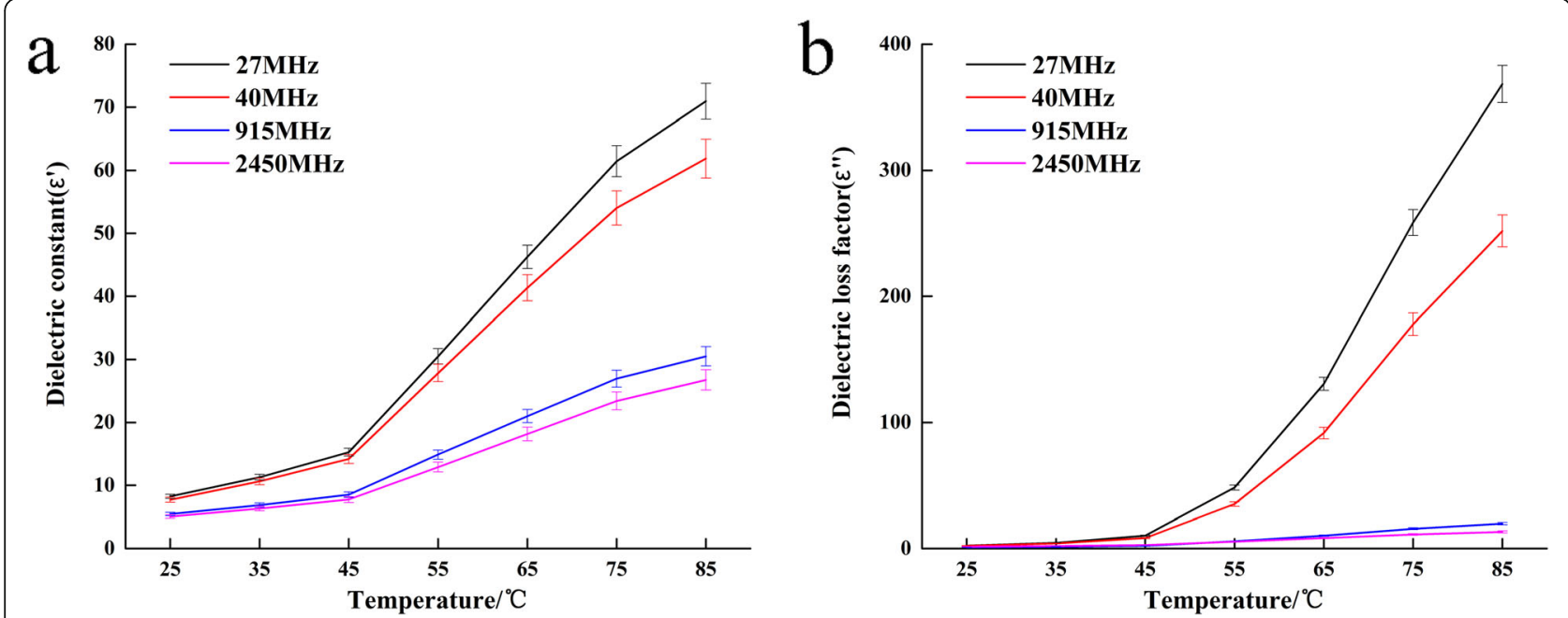

Fig. 5 Effect of frequency on dielectric constant $\varepsilon^{\prime}$ and dielectric loss factor $\varepsilon^{\prime \prime}$ at different temperatures of Pleurotus eryngii powder samples with moisture content of $21.2 \%$ a Dielectric constant $\left(\varepsilon^{\prime}\right)$ with moisture content of $21.2 \%$, $\mathbf{b}$ dielectric loss factor $\left(\varepsilon^{\prime \prime}\right)$ with moisture content of $21.2 \%$

other frequency levels for Pleurotus eryngii powder. In addition, Fig. 8 shows that the other four edible fungi have the same moisture content-dependent dielectric properties as those of Pleurotus eryngii.

The effect of moisture content on dielectric properties depends on the free water and combined moisture content in food (Ozturk et al. 2016). With an increase in moisture content, the water molecules in the material gradually come close together to form multi-layered combined water ( $\mathrm{Li}$ et al. 2019), or even become free water, which accelerates the overall metabolism of Pleurotus eryngii powder and enhance the activity of internal ions. Consequently, the dielectric constant and the dielectric loss factor increase with increasing moisture content (Ahmed et al. 2020).

\section{Regression analysis}

Table 1 shows the regression models used in this study to describe the dielectric properties of the five types of edible fungi powder as a function of temperature and moisture content at frequencies of $27,40,915$, and 2450 $\mathrm{MHz}$. Table 2 shows the regression equations and the correlation coefficient $\mathrm{R}^{2}$ for the relationship between the dielectric constant and dielectric loss factor and moisture content and temperature at different frequencies.
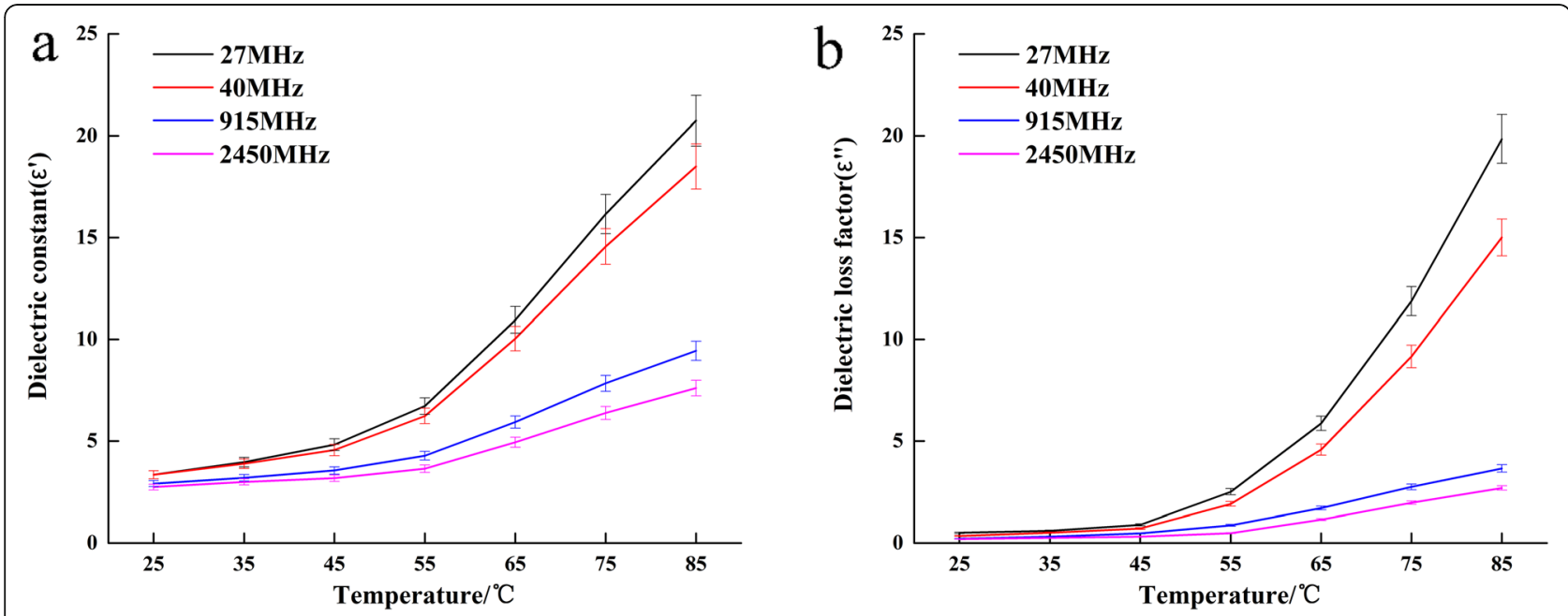

Fig. 6 Effect of frequency on dielectric constant $\varepsilon^{\prime}$ and dielectric loss factor $\varepsilon^{\prime \prime}$ at different temperatures of Velvet mushroom powder samples with moisture content of $10.5 \%$ a Dielectric constant $\left(\varepsilon^{\prime}\right)$ with moisture content of $10.5 \%$, b dielectric loss factor $\left(\varepsilon^{\prime \prime}\right)$ with moisture content of $10.5 \%$ 

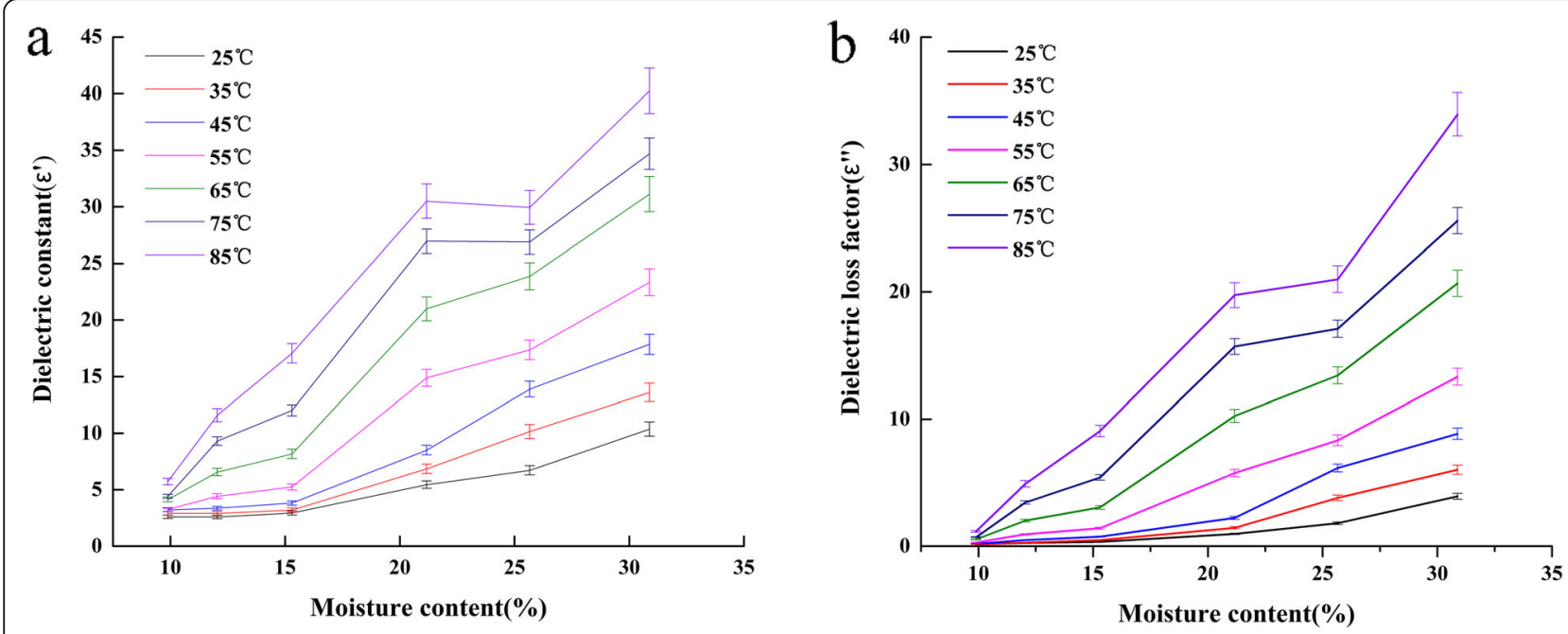

Fig. 7 Effect of moisture content on dielectric constant $\varepsilon^{\prime}$ and dielectric loss factor $\varepsilon^{\prime \prime}$ at different temperatures of Pleurotus eryngii powder samples with frequency of $915 \mathrm{MHz}$ a Dielectric constant $\left(\varepsilon^{\prime}\right)$ with frequency of $915 \mathrm{MHz}$, b dielectric loss factor ( $\left.\varepsilon^{\prime \prime}\right)$ with frequency of $915 \mathrm{MHz}$

According to the regression equation model established using regression analysis, the dielectric constant and dielectric loss factor of any moisture content and temperature can be obtained at a known frequency. Simultaneously, the moisture content of the sample can also be obtained through the equation model under the conditions of known temperature and dielectric properties. This equation model provides basic data for the online monitoring of sample moisture content and serves as guidance for the research and production of equipment to measure/monitor sample moisture content.

\section{Determination of power penetration depth}

According to the dielectric constant and dielectric loss factor of Pleurotus eryngii powder obtained under different moisture contents, temperatures, and frequencies, the penetration depths of Pleurotus eryngii and Agaricus bisporus powder were calculated using formula (3) in Tables 2 and 3, respectively. Both tables show that the penetration depth decreases as the temperature, moisture content, and frequency increase. Considering Pleurotus eryngii with a moisture content of $12.0 \%$ as an example, at a frequency of $27 \mathrm{MHz}$, the penetration

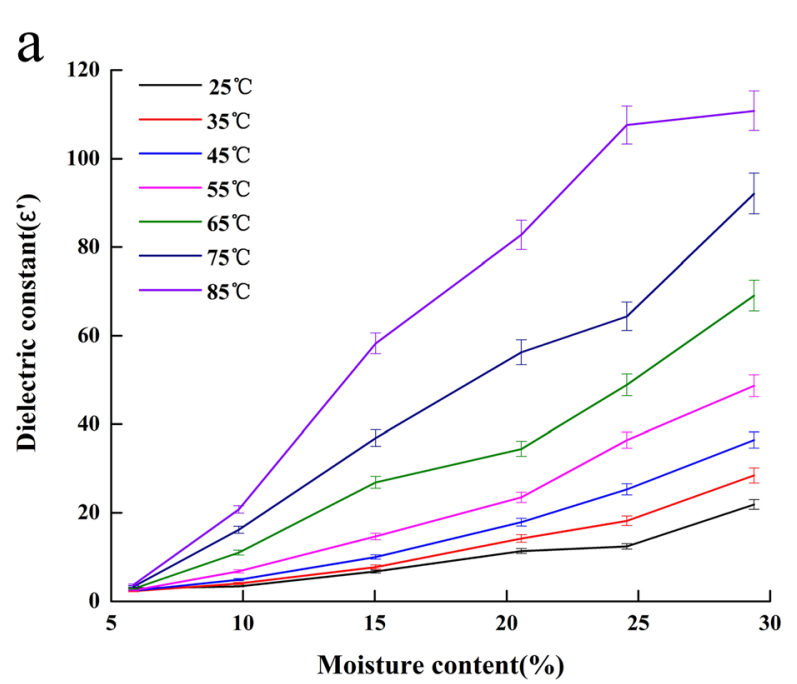

b

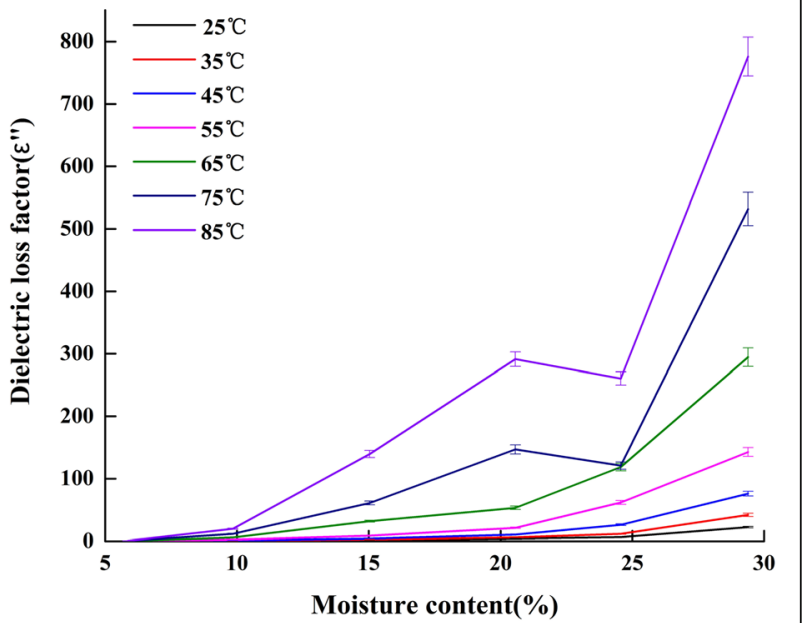

Fig. 8 Effect of moisture content on dielectric constant $\varepsilon^{\prime}$ and dielectric loss factor ( $\left.\varepsilon^{\prime \prime}\right)$ at different temperatures of Flammulina velutipes powder samples with frequency of $27 \mathrm{MHz}$ a Dielectric constant $\left(\varepsilon^{\prime}\right)$ with frequency of $27 \mathrm{MHz}$, b dielectric loss factor $\left(\varepsilon^{\prime \prime}\right)$ with frequency of $27 \mathrm{MHz}$ 
Table 1 Regression equations and correlation coefficients of dielectric properties for five edible fungi powders $\left(R^{2}\right)$

\begin{tabular}{|c|c|c|}
\hline Frequency (MHz) & Dielectric constant $\left(\varepsilon^{\prime}\right)$ & Dielectric loss factor $\left(\varepsilon^{\prime \prime}\right)$ \\
\hline \multicolumn{3}{|l|}{ Pleurotus eryngii } \\
\hline 27 & $\varepsilon^{\prime}=-74.9158+0.8672 T+297.5579 W\left(R^{2}=0.9495\right)$ & $\varepsilon^{\prime \prime}=-392.792+4.4708 \mathrm{~T}+1266.036 \mathrm{~W}\left(R^{2}=0.9424\right)$ \\
\hline 40 & $\varepsilon^{\prime}=-56.9852+0.6875 T+231.8879 W\left(R^{2}=0.9457\right)$ & $\varepsilon^{\prime \prime}=-266.215+3.03976 \mathrm{~T}+859.9247 \mathrm{~W}\left(R^{2}=0.9454\right)$ \\
\hline 915 & $\varepsilon^{\prime}=-22.9905+0.3017 \top+99.70858 \mathrm{~W}\left(R^{2}=0.9684\right)$ & $\varepsilon^{\prime \prime}=-20.0743+0.23216 \mathrm{~T}+72.4287 \mathrm{~W}\left(R^{2}=0.9869\right)$ \\
\hline 2450 & $\varepsilon^{\prime}=-18.6761+0.2496 \mathrm{~T}+81.7795 \mathrm{~W}\left(R^{2}=0.9546\right)$ & $\varepsilon^{\prime \prime}=-12.3889+0.14357 \mathrm{~T}+48.7449 \mathrm{~W}\left(R^{2}=0.9627\right)$ \\
\hline \multicolumn{3}{|c|}{ Flammulina velutipes } \\
\hline 27 & $\varepsilon^{\prime}=-60.3683+0.8701 \mathrm{~T}+235.3554 \mathrm{~W}\left(R^{2}=0.944\right)$ & $\varepsilon^{\prime \prime}=-299.52+3.7894 \mathrm{~T}+970.2958 \mathrm{~W}\left(R^{2}=0.919\right)$ \\
\hline 40 & $\varepsilon^{\prime}=-47.1171+0.6826 \mathrm{~T}+193.8688 \mathrm{~W}\left(R^{2}=0.949\right)$ & $\varepsilon^{\prime \prime}=-205.114+2.6039 \top+667.2806 \mathrm{~W}\left(R^{2}=0.9318\right)$ \\
\hline 915 & $\varepsilon^{\prime}=-17.0753+0.2668 \mathrm{~T}+80.9498 \mathrm{~W}\left(R^{2}=0.9276\right)$ & $\varepsilon^{\prime \prime}=-16.6038+0.2195 T+60.9836 \mathrm{~W}\left(R^{2}=0.9024\right)$ \\
\hline 2450 & $\varepsilon^{\prime}=-12.971+0.2077 T+63.0395 W\left(R^{2}=0.9203\right)$ & $\varepsilon^{\prime \prime}=-10.2345+0.1329 T+40.946 \mathrm{~W}\left(R^{2}=0.9868\right)$ \\
\hline \multicolumn{3}{|l|}{ Agaricus bisporus } \\
\hline 27 & $\varepsilon^{\prime}=-65.3171+0.9818 T+235.9902 W\left(R^{2}=0.9362\right)$ & $\varepsilon^{\prime \prime}=-416.175+6.2894 \mathrm{~T}+1112.254 \mathrm{~W}\left(R^{2}=0.9791\right)$ \\
\hline 40 & $\varepsilon^{\prime}=-52.1488+0.7962 T+193.9608 \mathrm{~W}\left(R^{2}=0.9434\right)$ & $\varepsilon^{\prime \prime}=-283.77+4.2883 \mathrm{~T}+763.7767 \mathrm{~W}\left(R^{2}=0.9337\right)$ \\
\hline 915 & $\varepsilon^{\prime}=-18.3079+0.2903 T+76.3639 W\left(R^{2}=0.9556\right)$ & $\varepsilon^{\prime \prime}=-21.1307+0.3157 \mathrm{~T}+65.1009 \mathrm{~W}\left(R^{2}=0.978\right)$ \\
\hline 2450 & $\varepsilon^{\prime}=-13.6822+0.2265 T+58.1319 W\left(R^{2}=0.9489\right)$ & $\varepsilon^{\prime \prime}=-11.8995+0.1744 T+39.834 W\left(R^{2}=0.9119\right)$ \\
\hline \multicolumn{3}{|l|}{ Velvet mushroom } \\
\hline 27 & $\varepsilon^{\prime}=-55.9134+0.8158 T+201.5411 W\left(R^{2}=0.9171\right)$ & $\varepsilon^{\prime \prime}=-261.638+3.5709 \top+712.8062 \mathrm{~W}\left(R^{2}=0.9673\right)$ \\
\hline 40 & $\varepsilon^{\prime}=-42.0661+0.6263 T+158.5781 W\left(R^{2}=0.9338\right)$ & $\varepsilon^{\prime \prime}=-179.433+2.4546 \mathrm{~T}+532.6113 \mathrm{~W}\left(R^{2}=0.9732\right)$ \\
\hline 915 & $\varepsilon^{\prime}=-13.4923+0.2249 \mathrm{~T}+58.3516 \mathrm{~W}\left(R^{2}=0.944\right)$ & $\varepsilon^{\prime \prime}=-14.1945+0.1977 T+47.0965 \mathrm{~W}\left(R^{2}=0.9736\right)$ \\
\hline 2450 & $\varepsilon^{\prime}=-10.0243+0.1784 T+44.9965 \mathrm{~W}\left(R^{2}=0.9335\right)$ & $\varepsilon^{\prime \prime}=-8.1648+0.1133 T+29.5383 \mathrm{~W}\left(R^{2}=0.9134\right)$ \\
\hline \multicolumn{3}{|l|}{ Straw mushroom } \\
\hline 27 & $\varepsilon^{\prime}=-64.6363+0.8826 T+253.2708 W\left(R^{2}=0.9162\right)$ & $\varepsilon^{\prime \prime}=-349.441+4.6281 T+1092.099 \mathrm{~W}\left(R^{2}=0.9693\right)$ \\
\hline 40 & $\varepsilon^{\prime}=-53.3488+0.7265 T+216.0695 \mathrm{~W}\left(R^{2}=0.9272\right)$ & $\varepsilon^{\prime \prime}=-239.195+3.1689 T+752.551 \mathrm{~W}\left(R^{2}=0.9749\right)$ \\
\hline 915 & $\varepsilon^{\prime}=-19.4398+0.2747 \mathrm{~T}+87.3258 \mathrm{~W}\left(R^{2}=0.9462\right)$ & $\varepsilon^{\prime \prime}=-19.2365+0.2528 T+68.4678 W\left(R^{2}=0.9654\right)$ \\
\hline 2450 & $\varepsilon^{\prime}=-14.9895+0.2196 \mathrm{~T}+68.7421 \mathrm{~W}\left(R^{2}=0.9373\right)$ & $\varepsilon^{\prime \prime}=-11.175+0.1469 \top+42.8537 \mathrm{~W}\left(R^{2}=0.907\right)$ \\
\hline
\end{tabular}

depth is reduced from $430 \mathrm{~cm}$ to $29 \mathrm{~cm}$ during the temperature rise from $25^{\circ} \mathrm{C}$ to $85^{\circ} \mathrm{C}$. Under a constant temperature and frequency, such $915 \mathrm{MHz}$ and $35^{\circ} \mathrm{C}$, the moisture content increases from 9.9 to $30.9 \%$, and the penetration depth of Pleurotus eryngii decreases from $58 \mathrm{~cm}$ to $3.3 \mathrm{~cm}$. Simultaneously, the penetration depth decreases from $95 \mathrm{~cm}$ to $2.8 \mathrm{~cm}$ with the frequency increasing from $27 \mathrm{MHz}$ to $2450 \mathrm{MHz}$ under a constant temperature and moisture content, such as a $25^{\circ} \mathrm{C}$ and $25.7 \%$. Table 2 indicates that the relationships between the dielectric properties and penetration depths of the other four edible fungi were similar to those of Pleurotus eryngii. In addition, in some studies on wheat flour and soybean flour, the same penetration depths with respect to frequency, temperature, and moisture content as those of Pleurotus eryngii powder were obtained (Wang et al. 2006).

It is also evident from Tables 2 and 3 that the penetration depth at lower frequencies $(<100 \mathrm{MHz})$ is significantly greater than that at higher frequencies.
This implies that the uniformity of RF heating at lower frequencies is substantially greater than that at higher frequencies. Compared with the lower RF, the power penetration depth of Pleurotus eryngii is smaller under the effect of higher microwave frequencies, indicating that more heat is on the surface of the material in the microwave heating process. Foods with higher moisture contents have higher dielectric properties and correspondingly lower energy penetration depths, and the majority of foods have a smaller power penetration depth under the effect of shortwavelength electromagnetic waves such as microwaves. It indicates that when drying Pleurotus eryngii, radio frequencies of 27 and $40 \mathrm{MHz}$ can be used for large depth processing, while radio frequencies of 915 and $2450 \mathrm{MHz}$ can be used for small-depth processing.

It is worth noting that the penetration depth of electromagnetic waves acting on materials is different. In the study of the dielectric properties of bread, the relation 
Table 2 The calculated penetration depths of Pleurotus eryngii powder under different moisture contents and temperatures

\begin{tabular}{|c|c|c|c|c|c|c|c|c|}
\hline \multirow{3}{*}{$\begin{array}{l}\text { Moisture } \\
\text { content }\end{array}$} & \multirow{3}{*}{$\begin{array}{l}\text { Frequency } \\
\text { (MHz) }\end{array}$} & \multicolumn{7}{|c|}{ Penetration depth $(\mathrm{m})$} \\
\hline & & \multicolumn{7}{|l|}{ Temperature } \\
\hline & & $25^{\circ} \mathrm{C}$ & $35^{\circ} \mathrm{C}$ & $45^{\circ} \mathrm{C}$ & $55^{\circ} \mathrm{C}$ & $65^{\circ} \mathrm{C}$ & $75^{\circ} \mathrm{C}$ & $85^{\circ} \mathrm{C}$ \\
\hline \multirow[t]{4}{*}{$9.9 \%$} & 27 & $124.61 \pm 0.05$ & $67.28 \pm 0.03$ & $12.04 \pm 0.02$ & $11.01 \pm 0.09$ & $16.82 \pm 0.13$ & $7.95 \pm 0.09$ & $2.66 \pm 0.04$ \\
\hline & 40 & $37.61 \pm 0.04$ & $20.14 \pm 0.05$ & $33.89 \pm 0.06$ & $25.23 \pm 0.11$ & $4.25 \pm 0.05$ & $3.04 \pm 0.04$ & $1.57 \pm 0.03$ \\
\hline & 915 & $0.57 \pm 0.01$ & $0.58 \pm 0.01$ & $0.47 \pm 0.08$ & $0.32 \pm 0.12$ & $0.20 \pm 0.12$ & $0.16 \pm 0.05$ & $0.11 \pm 0.03$ \\
\hline & 2450 & $0.22 \pm 0.01$ & $0.13 \pm 0.07$ & $0.089 \pm 0.02$ & $0.074 \pm 0.09$ & $0.054 \pm 0.17$ & $0.05 \pm 0.25$ & $0.033 \pm 0.11$ \\
\hline \multirow[t]{4}{*}{$12.0 \%$} & 27 & $4.30 \pm 0.01$ & $5.58 \pm 0.03$ & $3.24 \pm 0.12$ & $2.42 \pm 0.05$ & $0.96 \pm 0.01$ & $0.46 \pm 0.03$ & $0.29 \pm 0.12$ \\
\hline & 40 & $2.74 \pm 0.05$ & $3.18 \pm 0.01$ & $2.11 \pm 0.02$ & $1.66 \pm 0.04$ & $0.75 \pm 0.01$ & $0.38 \pm 0.01$ & $0.24 \pm 0.19$ \\
\hline & 915 & $0.48 \pm 0.07$ & $0.33 \pm 0.12$ & $0.20 \pm 0.05$ & $0.12 \pm 0.08$ & $0.067 \pm 0.15$ & $0.047 \pm 0.19$ & $0.037 \pm 0.12$ \\
\hline & 2450 & $0.11 \pm 0.14$ & $0.091 \pm 0.11$ & $0.066 \pm 0.15$ & $0.042 \pm 0.18$ & $0.027 \pm 0.11$ & $0.019 \pm 0.07$ & $0.016 \pm 0.07$ \\
\hline \multirow[t]{4}{*}{$15.3 \%$} & 27 & $6.96 \pm 0.03$ & $5.12 \pm 0.15$ & $2.72 \pm 0.01$ & $1.03 \pm 0.06$ & $0.47 \pm 0.15$ & $0.25 \pm 0.09$ & $0.15 \pm 0.05$ \\
\hline & 40 & $4.67 \pm 0.21$ & $3.39 \pm 0.02$ & $2.02 \pm 0.08$ & $0.86 \pm 0.14$ & $0.39 \pm 0.12$ & $0.21 \pm 0.17$ & $0.12 \pm 0.03$ \\
\hline & 915 & $0.26 \pm 0.11$ & $0.20 \pm 0.01$ & $0.14 \pm 0.05$ & $0.086 \pm 0.17$ & $0.050 \pm 0.24$ & $0.034 \pm 0.17$ & $0.025 \pm 0.11$ \\
\hline & 2450 & $0.089 \pm 0.19$ & $0.066 \pm 0.11$ & $0.044 \pm 0.12$ & $0.036 \pm 0.11$ & $0.020 \pm 0.03$ & $0.014 \pm 0.15$ & $0.011 \pm 0.19$ \\
\hline \multirow[t]{4}{*}{$21.2 \%$} & 27 & $2.19 \pm 0.05$ & $1.34 \pm 0.07$ & $0.71 \pm 0.03$ & $0.24 \pm 0.11$ & $0.13 \pm 0.16$ & $0.088 \pm 0.29$ & $0.072 \pm 0.15$ \\
\hline & 40 & $1.51 \pm 0.15$ & $0.96 \pm 0.16$ & $0.56 \pm 0.01$ & $0.20 \pm 0.18$ & $0.11 \pm 0.01$ & $0.074 \pm 0.05$ & $0.060 \pm 0.14$ \\
\hline & 915 & $0.13 \pm 0.24$ & $0.095 \pm 0.34$ & $0.069 \pm 0.33$ & $0.036 \pm 0.14$ & $0.024 \pm 0.34$ & $0.018 \pm 0.14$ & $0.015 \pm 0.11$ \\
\hline & 2450 & $0.028 \pm 0.34$ & $0.023 \pm 0.16$ & $0.020 \pm 0.18$ & $0.013 \pm 0.15$ & $0.010 \pm 0.17$ & $0.009 \pm 0.15$ & $0.008 \pm 0.16$ \\
\hline \multirow[t]{4}{*}{$25.7 \%$} & 27 & $0.95 \pm 0.01$ & $0.41 \pm 0.04$ & $0.25 \pm 0.05$ & $0.18 \pm 0.08$ & $0.11 \pm 0.27$ & $0.081 \pm 0.21$ & $0.068 \pm 0.16$ \\
\hline & 40 & $0.76 \pm 0.13$ & $0.34 \pm 0.14$ & $0.21 \pm 0.05$ & $0.15 \pm 0.15$ & $0.089 \pm 0.17$ & $0.068 \pm 0.18$ & $0.057 \pm 0.17$ \\
\hline & 915 & $0.076 \pm 0.11$ & $0.044 \pm 0.26$ & $0.032 \pm 0.02$ & $0.027 \pm 0.01$ & $0.020 \pm 0.06$ & $0.017 \pm 0.06$ & $0.014 \pm 0.01$ \\
\hline & 2450 & $0.028 \pm 0.05$ & $0.018 \pm 0.05$ & $0.013 \pm 0.04$ & $0.011 \pm 0.03$ & $0.009 \pm 0.02$ & $0.0084 \pm 0.1$ & $0.0077 \pm 0.2$ \\
\hline \multirow[t]{4}{*}{$30.9 \%$} & 27 & $0.43 \pm 0.03$ & $0.27 \pm 0.05$ & $0.18 \pm 0.04$ & $0.11 \pm 0.06$ & $0.075 \pm 0.08$ & $0.062 \pm 0.11$ & $0.051 \pm 0.24$ \\
\hline & 40 & $0.35 \pm 0.14$ & $0.23 \pm 0.15$ & $0.15 \pm 0.08$ & $0.09 \pm 0.01$ & $0.062 \pm 0.02$ & $0.052 \pm 0.05$ & $0.042 \pm 0.05$ \\
\hline & 915 & $0.044 \pm 0.27$ & $0.033 \pm 0.29$ & $0.026 \pm 0.06$ & $0.020 \pm 0.09$ & $0.015 \pm 0.01$ & $0.013 \pm 0.03$ & $0.010 \pm 0.01$ \\
\hline & 2450 & $0.016 \pm 0.04$ & $0.013 \pm 0.09$ & $0.0103 \pm 0.03$ & $0.0085 \pm 0.05$ & $0.0072 \pm 0.1$ & $0.0067 \pm 0.02$ & $0.0059 \pm 0.01$ \\
\hline
\end{tabular}

between the penetration depth and temperature, frequency, and moisture content is the same as the variation in penetration depth of electromagnetic waves on Pleurotus eryngii (Liu et al. 2009). The study of the penetration depth of electromagnetic waves on mashed potatoes showed an opposite trend as those of bread and Pleurotus eryngii (Guan et al. 2004).

When RF waves reach the inside of food, their electromagnetic energy will decay, and the power penetration depth is an important indicator for measuring their heating effect. When the penetration depth is small, more electromagnetic waves act on the surface of the food, resulting in an abnormal temperature rise on the surface of the food. This also indicates that the uniformity of the medium drying is greater at lower radio frequencies than that at the microwave frequency. Therefore, for evenly dried food materials, the thickness should not exceed two to three times the penetration depth (Jiao et al. 2011).

\section{Conclusions}

The findings of this study indicated that the dielectric properties $\left(\varepsilon^{\prime}\right.$ and $\left.\varepsilon^{\prime \prime}\right)$ of edible fungi were closely related to their moisture content, frequency, and temperature. The dielectric constant $\varepsilon^{\prime}$ and loss factor $\varepsilon$ " of edible fungi powder increased with moisture content and temperature and decreased with increasing frequency. At higher temperatures $\left(>45^{\circ} \mathrm{C}\right)$, the effect of frequency on dielectric constant $\varepsilon^{\prime}$ and dielectric loss factor $\varepsilon$ " was more prominent than at lower temperatures; the effect of frequency on dielectric constant $\varepsilon^{\prime}$ and dielectric loss factor $\varepsilon$ " was more evident at higher moisture content; the variation of frequency on dielectric constant $\varepsilon^{\prime}$ and dielectric loss factor $\varepsilon$ " is more noticeable at lower frequencies. The regression analysis polynomial equation model can be used to characterize the values of the dielectric constant and dielectric loss factor as a function of temperature and moisture content at a certain 
Table 3 The calculated penetration depths of Agaricus bisporus powder at different moisture contents and temperatures

\begin{tabular}{|c|c|c|c|c|c|c|c|c|}
\hline \multirow{3}{*}{$\begin{array}{l}\text { Moisture } \\
\text { content }\end{array}$} & \multirow{3}{*}{$\begin{array}{l}\text { Frequency } \\
\text { (MHz) }\end{array}$} & \multicolumn{7}{|c|}{ Penetration depth (m) } \\
\hline & & \multicolumn{7}{|l|}{ Temperature } \\
\hline & & $25^{\circ} \mathrm{C}$ & $35^{\circ} \mathrm{C}$ & $45^{\circ} \mathrm{C}$ & $55^{\circ} \mathrm{C}$ & $65^{\circ} \mathrm{C}$ & $75^{\circ} \mathrm{C}$ & $85^{\circ} \mathrm{C}$ \\
\hline \multirow[t]{4}{*}{$6.2 \%$} & 27 & $6.80 \pm 0.05$ & $4.98 \pm 0.03$ & $4.75 \pm 0.01$ & $4.26 \pm 0.15$ & $5.11 \pm 0.28$ & $5.93 \pm 0.23$ & $20.17 \pm 0.32$ \\
\hline & 40 & $4.01 \pm 0.04$ & $3.31 \pm 0.04$ & $3.30 \pm 0.05$ & $3.07 \pm 0.12$ & $3.40 \pm 0.18$ & $4.00 \pm 0.19$ & $8.44 \pm 0.21$ \\
\hline & 915 & $0.51 \pm 0.11$ & $0.57 \pm 0.01$ & $0.57 \pm 0.02$ & $0.51 \pm 0.01$ & $0.46 \pm 0.04$ & $0.39 \pm 0.06$ & $0.27 \pm 0.15$ \\
\hline & 2450 & $1.20 \pm 0.24$ & $1.72 \pm 0.11$ & $1.82 \pm 0.04$ & $7.28 \pm 0.25$ & $3.50 \pm 0.08$ & $0.88 \pm 0.03$ & $0.30 \pm 0.11$ \\
\hline \multirow[t]{4}{*}{$11.0 \%$} & 27 & $156.26 \pm 0.11$ & $18.64 \pm 0.23$ & $3.29 \pm 0.09$ & $0.79 \pm 0.05$ & $0.28 \pm 0.12$ & $0.14 \pm 0.03$ & $0.11 \pm 0.05$ \\
\hline & 40 & $25.96 \pm 0.17$ & $25.30 \pm 0.03$ & $2.50 \pm 0.07$ & $0.65 \pm 0.04$ & $0.23 \pm 0.06$ & $0.12 \pm 0.01$ & $0.09 \pm 0.02$ \\
\hline & 915 & $1.02 \pm 0.04$ & $0.50 \pm 0.15$ & $0.22 \pm 0.01$ & $0.09 \pm 0.04$ & $0.04 \pm 0.01$ & $0.03 \pm 0.01$ & $0.02 \pm 0.01$ \\
\hline & 2450 & $0.28 \pm 0.05$ & $0.15 \pm 0.01$ & $0.07 \pm 0.09$ & $0.04 \pm 0.01$ & $0.02 \pm 0.01$ & $0.013 \pm 0.01$ & $0.011 \pm 0.01$ \\
\hline \multirow[t]{4}{*}{$16.7 \%$} & 27 & $4.66 \pm 0.03$ & $1.71 \pm 0.01$ & $0.59 \pm 0.04$ & $0.24 \pm 0.01$ & $0.11 \pm 0.01$ & $0.10 \pm 0.01$ & $0.08 \pm 0.01$ \\
\hline & 40 & $2.98 \pm 0.16$ & $1.31 \pm 0.01$ & $0.49 \pm 0.17$ & $0.20 \pm 0.01$ & $0.09 \pm 0.04$ & $0.08 \pm 0.01$ & $0.06 \pm 0.01$ \\
\hline & 915 & $0.32 \pm 0.17$ & $0.16 \pm 0.04$ & $0.08 \pm 0.01$ & $0.04 \pm 0.01$ & $0.019 \pm 0.01$ & $0.017 \pm 0.01$ & $0.014 \pm 0.01$ \\
\hline & 2450 & $0.08 \pm 018$ & $0.06 \pm 0.01$ & $0.03 \pm 0.01$ & $0.02 \pm 0.01$ & $0.0104 \pm 0.03$ & $0.0095 \pm 0.01$ & $0.008 \pm 0.01$ \\
\hline \multirow[t]{4}{*}{$20.4 \%$} & 27 & $1.09 \pm 0.01$ & $0.73 \pm 0.01$ & $0.41 \pm 0.01$ & $0.22 \pm 0.01$ & $0.13 \pm 0.01$ & $0.08 \pm 0.01$ & $0.05 \pm 0.01$ \\
\hline & 40 & $0.86 \pm 0.13$ & $0.59 \pm 0.05$ & $0.35 \pm 0.01$ & $0.18 \pm 0.01$ & $0.11 \pm 0.01$ & $0.07 \pm 0.01$ & $0.04 \pm 0.01$ \\
\hline & 915 & $0.10 \pm 0.11$ & $0.09 \pm 0.01$ & $0.06 \pm 0.01$ & $0.03 \pm 0.01$ & $0.02 \pm 0.01$ & $0.014 \pm 0.01$ & $0.010 \pm 0.01$ \\
\hline & 2450 & $0.04 \pm 0.17$ & $0.034 \pm 0.01$ & $0.026 \pm 0.01$ & $0.016 \pm 0.01$ & $0.011 \pm 0.01$ & $0.008 \pm 0.01$ & $0.006 \pm 0.01$ \\
\hline \multirow[t]{4}{*}{$25.9 \%$} & 27 & $0.42 \pm 0.17$ & $0.30 \pm 0.01$ & $0.18 \pm 0.01$ & $0.12 \pm 0.01$ & $0.08 \pm 0.01$ & $0.06 \pm 0.01$ & $0.05 \pm 0.01$ \\
\hline & 40 & $0.35 \pm 0.11$ & $0.26 \pm 0.02$ & $0.15 \pm 0.02$ & $0.10 \pm 0.01$ & $0.07 \pm 0.01$ & $0.05 \pm 0.01$ & $0.04 \pm 0.01$ \\
\hline & 915 & $0.05 \pm 0.18$ & $0.04 \pm 0.01$ & $0.03 \pm 0.01$ & $0.02 \pm 0.01$ & $0.015 \pm 0.01$ & $0.011 \pm 0.01$ & $0.0103 \pm 0.01$ \\
\hline & 2450 & $0.02 \pm 0.19$ & $0.02 \pm 0.01$ & $0.014 \pm 0.01$ & $0.010 \pm 0.01$ & $0.008 \pm 0.01$ & $0.0064 \pm 0.01$ & $0.0059 \pm 0.01$ \\
\hline \multirow[t]{4}{*}{$31.2 \%$} & 27 & $0.22 \pm 0.17$ & $0.18 \pm 0.01$ & $0.15 \pm 0.01$ & $0.11 \pm 0.01$ & $0.09 \pm 0.01$ & $0.07 \pm 0.01$ & $0.054 \pm 0.01$ \\
\hline & 40 & $0.18 \pm 0.19$ & $0.15 \pm 0.02$ & $0.12 \pm 0.01$ & $0.09 \pm 0.01$ & $0.07 \pm 0.01$ & $0.05 \pm 0.01$ & $0.044 \pm 0.01$ \\
\hline & 915 & $0.032 \pm 0.17$ & $0.028 \pm 0.02$ & $0.024 \pm 0.01$ & $0.019 \pm 0.01$ & $0.015 \pm 0.01$ & $0.012 \pm 0.01$ & $0.010 \pm 0.01$ \\
\hline & 2450 & $0.015 \pm 0.21$ & $0.013 \pm 0.02$ & $0.011 \pm 0.01$ & $0.009 \pm 0.01$ & $0.008 \pm 0.01$ & $0.007 \pm 0.01$ & $0.006 \pm 0.01$ \\
\hline
\end{tabular}

frequency. The establishment of this equation model provides basic data for online monitoring of sample moisture content and also offers a reference for the research and production of equipment to measure/ monitor sample moisture content. The penetration depth of electromagnetic waves decreases with increasing frequency, temperature, and moisture content of the sample. Therefore, radio frequencies below 100 $\mathrm{MHz}$ and higher microwave frequencies can be used for large-scale and small-scale processing of edible fungi, respectively. This study provides useful information for drying edible fungus with radio-frequency or microwave energy and designing dielectric drying equipment.

\section{Abbreviation}

RF: Radio-frequency

\section{Acknowledgements}

we are grateful to the support provided by the National Key R\&D Program of China (No. 2018YFD0400200), China National Natural Science Foundation
(No. 31601484), and Jiangsu Agricultural Scientific and Technological SelfInnovation Foundation [CX(18)3037].

\section{Authors' contributions}

Authors contributed equality to the reported work. The author read and approved the final manuscript.

\section{Funding}

The authors are thankful for the support provided by the National Key R\&D Program of China (No. 2018YFD0400200), China National Natural Science Foundation (No. 31601484), and Jiangsu Agricultural Scientific and Technological Self-Innovation Foundation [CX(18)3037].

\section{Availability of data and materials}

The datasets used or analysed during the current study are available from the corresponding author on reasonable request.

\section{Declarations}

Ethics approval and consent to participate

Not applicable.

Consent for publication

Not applicable. 


\section{Competing interests}

Not applicable.

\section{Author details \\ 'Institute of Farm Product Processing, Jiangsu Academy of Agricultural Sciences, Nanjing 210014, People's Republic of China. ${ }^{2}$ College of Food Science and Engineering, Yangzhou University, Yangzhou 225127, People's Republic of China. ${ }^{3}$ College of Food and Bioengineering, Jiangsu University, Zhenjiang 212013, People's Republic of China. ${ }^{4}$ College of Food Science and Technology, Nanjing Agricultural University, Nanjing 210095, People's Republic of China. 'State Key Laboratory of Food Science and Technology, Jiangnan University, Wuxi 214122, People's Republic of China.}

\section{Received: 28 September 2020 Accepted: 9 April 2021}

Published online: 01 June 2021

\section{References}

Ahmed, J., Thomas, L., \& Khashawi, R. (2020). Influence of hot - air drying and freeze - drying on functional, rheological, structural and dielectric properties of green banana flour and dispersions. Food Hydrocolloid, 99, 105331. https:// doi.org/10.1016/j.foodhyd.2019.105331.

Auksornsri, T., Tang, J., Tang, Z., Lin, H., \& Songsermpong, S. (2018). Dielectric properties of rice model food systems relevant to microwave sterilization process. Innovative Food Science \& Emerging Technologies, 45, 98-105. https:// doi.org/10.1016/j.ifset.2017.09.002.

Bedane, T. F., Chen, L., Marra, F., \& Wang, S. (2017). Experimental study of radio frequency (RF) thawing of foods with movement on conveyor belt. Journal of Food Engineering, 201, 17-25. https://doi.org/10.1016/j.jfoodeng.2017.01.01

Cong, H., Liu, F., Tang, Z., \& Xue, C. (2012). Dielectric properties of sea cucumbers (Stichopus japonicus) and model foods at $915 \mathrm{MHz}$. Journal of Food Engineering, 109(3), 635-639. https://doi.org/10.1016/j.jfoodeng.2011.06.012.

Erdogdu, S. B., Eliasson, L., Erdogdu, F., Isaksson, S., \& Ahrné, L. (2015). Experimental determination of penetration depths of various spice commodities (black pepper seeds, paprika powder and oregano leaves) under infrared radiation. Journal of Food Engineering, 161, 75-81. https://doi. org/10.1016/j.jfoodeng.2015.03.036.

Ewa, J. R., Katarzyna, S., Aneta, S., Wojciech, R., \& Waldemar, G. (2019). Lactic acid fermentation of edible mushrooms: Tradition, technology, current state of research: A review. Comprehensive Reviews in Food Science and Food Safety, $18,655-669$.

Guan, D., Cheng, M., Wang, Y., \& Tang, J. (2004). Dielectric properties of mashed potatoes relevant to microwave and radio-frequency pasteurization and sterilization processes. Journal of Food Science, 69(1), 30-37.

Guo, W., Wang, S., Tiwari, G., Johnson, J. A., \& Tang, J. (2009). Temperature and moisture dependent dielectric properties of legume flour associated with dielectric heating. LWT - Food Science and Technology, 43(2), 193-201.

Guo, W., \& Zhu, X. (2014). Dielectric properties of red pepper powder related to radiofrequency and microwave drying. Food and Bioprocess Technology, 7(12) 3591-3601. https://doi.org/10.1007/s11947-014-1375-x

Jiao, S., Johnson, J. A., Tang, J., Tiwari, G., \& Wang, S. (2011). Dielectric properties of cowpea weevil, black-eyed peas and mung beans with respect to the development of radio frequency heat treatments. Biosystems Engineering, 108(3), 280-291. https://doi.org/10.1016/j.biosystemseng.2010.12.010.

Khan, M. A., \& Tania, M. (2012). Nutritional and medicinal importance of Pleurotus Mushrooms: An overview. Food Research International, 28(3), 313-329. https:// doi.org/10.1080/87559129.2011.637267.

Lau, S. K., Dag, D., Ozturk, S., Kong, F., \& Subbiah, J. (2020). A comparison between the open-ended coaxial probe method and the parallel plate method for measuring the dielectric properties of low-moisture foods. LWT, 130, 109719. https://doi.org/10.1016/j.lwt.2020.109719.

Lau, S. K., \& Subbiah, J. (2018). An automatic system for measuring dielectric properties of foods: Albumen, yolk, and shell of fresh eggs. Journal of Food Engineering, 223, 79-90. https://doi.org/10.1016/j.jfoodeng.2017.11.039.

Li, L., Zhang, M., \& Yang, P. (2019). Suitability of LF-NMR to analysis water state and predict dielectric properties of Chinese yam during microwave vacuum drying. LWT, 105, 257-264. https://doi.org/10.1016/j.lwt.2019.02.017.

Li, R., Kou, X., Cheng, T., Zheng, A., \& Wang, S. (2017). Verification of radio frequency pasteurization process for in-shell almonds. Journal of Food Engineering, 192, 103-110. https://doi.org/10.1016/j.jfoodeng.2016.08.002.
Ling, B., Hou, L., Li, R., \& Wang, S. (2016). Storage stability of pistachios as influenced by radio frequency treatments for postharvest disinfestations. Innovative Food Science \& Emerging Technologies, 33, 357-364. https://doi. org/10.1016/j.ifset.2015.10.013.

Liu, Y., Tang, J., \& Mao, Z. (2009). Analysis of bread dielectric properties using mixture equations. Journal of Food Engineering, 93(1), 72-79. https://doi.org/1 0.1016/j.jfoodeng.2008.12.032

Manzi, P., Aguzzi, A., \& Pizzoferrato, L. (2001). Nutritional value of mushrooms widely consumed in Italy. Food Chemistry, 73(3), 321-325. https://doi.org/10.1 016/S0308-8146(00)00304-6.

Nagaraj, G., Purohit, A., Harrison, M., Singh, R., Hung, Y., \& Mohan, A. (2016). Radiofrequency pasteurization of inoculated ground beef homogenate. Food Control, 59, 59-67. https://doi.org/10.1016/j.foodcont.2015.04.020.

Ozturk, S., Kong, F., Trabelsi, S., \& Singh, R. K. (2016). Dielectric properties of dried vegetable powders and their temperature profile during radio frequency heating. Journal of Food Engineering, 169, 91-100. https://doi.org/10.1016/j. jfoodeng.2015.08.008.

Reis, F. S., Barros, L., Martins, A., \& Ferreira, I. C. F. R. (2012). Chemical composition and nutritional value of the most widely appreciated cultivated mushrooms: An inter-species comparative study. Food and Chemical Toxicology, 50(2), 191-197. https://doi.org/10.1016/j.fct.2011.10.056.

Su, D., LV, W., Wang, Y., Wang, L., \& Li, D. (2020). Influence of microwave hot-air flow rolling dry-blanching on microstructure, water migration and quality of Pleurotus eryngii during hot-air drying. Food Control, 114, 107228. https://doi. org/10.1016/j.foodcont.2020.107228.

Sun, Y., Zhang, M., \& Fang, Z. (2019). Efficient physical extraction of active constituents from edible fungi and their potential bioactivities: A review. Trends in Food Science and Technology, 105, 468-482. https://doi.org/10.101 6/j.tifs.2019.02.026.

Tian, Y., Zhao, Y., Huang, J., Zeng, H., \& Zheng, B. (2016). Effects of different drying methods on the product quality and volatile compounds of whole shiitake mushrooms. Food Chemistry, 197(Pt A), 714-722. https://doi.org/10.1016/j. foodchem.2015.11.029.

Walde, S. G., Velu, V., Jyothirmayi, T., \& Math, R. G. (2005). Effects of pretreatments and drying methods on dehydration of mushroom. Journal of Food Engineering, 74(1), 108-115.

Wang, S., Birla, S. L., Tang, J., \& Hansen, J. D. (2006). Postharvest treatment to control codling moth in fresh apples using water assisted radio frequency heating. Postharvest Biology and Technology, 40(1), 89-96. https://doi.org/10.1 016/j.postharvbio.2005.12.005.

Wang, W., Wang, W., Jung, J., Yang, R., Tang, J., \& Zhao, Y. (2020). Investigation of hot-air assisted radio frequency (HARF) dielectric heating for improving drying efficiency and ensuring quality of dried hazelnuts (Corylus avellana L.). Food and Bioproducts Processing, 120, 179-190. https://doi.org/10.1016/j.fbp.2 020.01.006

Wang, X., Liu, H., Zhang, J., Li, T., \& Wang, Y. (2017). Evaluation of heavy metal concentrations of edible wild-grown mushrooms from China. Journal of Environmental Health Science and Engineering, 52(3), 178-183. https://doi. org/10.1080/03601234.2017.1261545.

Xue, Y., Xie, J., Xu, X., Yong, L., Hu, B., Liang, J., ... Qing, L. (2019). UPLC-QqQ/MS combined with similarity assessment of 17 nucleic acid constituents in 147 edible fungi from Sichuan Basin, China. Food Research International, 120, 577 585. https://doi.org/10.1016/j.foodres.2018.11.008.

Yan, J., Ding, Z., Gao, X., Wang, Y., Yang, Y., Wu, D., \& Zhang, H. (2018). Comparative study of physicochemical properties and bioactivity of Hericium erinaceus polysaccharides at different solvent extractions. Carbohydrate Polymers, 193, 373-382. https://doi.org/10.1016/j.carbpol.2018.04.019.

Zhang, S., Zhou, L., Ling, B., \& Wang, S. (2016). Dielectric properties of peanut kernels associated with microwave and radio frequency drying. Biosystems Engineering, 145, 108-117. https://doi.org/10.1016/j.biosystemseng.2016.03. 002

Zhao, Y., Yang, J., Liu, Y., Zhao, M., \& Wang, J. (2018). Ultrasound assisted extraction of polysaccharides from Lentinus edodes and its anti-hepatitis $B$ activity in vitro. International Journal of Biological Macromolecules, 107(Pt B), 2217-2223. https://doi.org/10.1016/j.jibiomac.2017.10.100.

Zheng, A., Zhang, L., \& Wang, S. (2017). Verification of radio frequency pasteurization treatment for controlling Aspergillus parasiticus on corn grains. International Journal of Food Microbiology, 249, 27-34. https://doi.org/10.101 6/j.ijfoodmicro.2017.02.017.

Zhou, H., Guo, C., \& Wang, S. (2017). Performance comparison between the free running oscillator and $50 \Omega$ radio frequency systems. Innovative Food Science 
\& Emerging Technologies, 39, 171-178. https://doi.org/10.1016/j.fset.2016.12. 003.

Zhou, X., Gao, H., Mitcham, E. J., \& Wang, S. (2018). Comparative analyses of three dehydration methods on drying characteristics and oil quality of in-shell walnuts. Dry Technology, 36(4), 477-490. https://doi.org/10.1080/07373937.201 7.1351452.

Zhou, X., Li, R., Lyng, J., \& Wang, S. (2018). Dielectric properties of kiwifruit associated with a combined radio frequency vacuum and osmotic drying. Journal of Food Engineering, 239, 72-82. https://doi.org/10.1016/j.foodeng.201 8.07.006.

Zhu, X., Guo, W., \& Wu, X. (2012). Frequency - and temperature - dependent dielectric properties of fruit juices associated with pasteurization by dielectric heating. Journal of Food Engineering, 109(2), 258-266. https://doi.org/10.1016/ j.jfoodeng.2011.10.005.

\section{Publisher's Note}

Springer Nature remains neutral with regard to jurisdictional claims in published maps and institutional affiliations.

Ready to submit your research? Choose BMC and benefit from:

- fast, convenient online submission

- thorough peer review by experienced researchers in your field

- rapid publication on acceptance

- support for research data, including large and complex data types

- gold Open Access which fosters wider collaboration and increased citations

- maximum visibility for your research: over $100 \mathrm{M}$ website views per year

At $\mathrm{BMC}$, research is always in progress.

Learn more biomedcentral.com/submissions 